Communications in Physics, Vol. 27, No. 4 (2017), pp. 291-300

DOI:10.15625/0868-3166/27/4/10499

\title{
DEVELOPMENT OF A PC PROGRAM FOR MULTIVARIATE STATISTICAL ANALYSIS
}

\author{
PHAM NGOC SON ${ }^{\dagger}$, CAO DONG VU AND MAI QUYNH ANH \\ Nuclear Research Institute, 1 Nguyen Tu Luc, Dalat, Vietnam \\ $\dagger$ E-mail: pnson.nri@gmail.com
}

Received 7 July 2017

Accepted for publication 11 September 2017

Published 18 November 2017

\begin{abstract}
This report introduces a new computer program, so-called MSAP-1.0, which has been developed at the Dalat Nuclear Research Institute, for data processing and interpretation of the experimental data sheets based on the multivariate data analysis techniques. In this preliminary version of the program, the dimensions of a given data set to be analyzed are up to 50 variables and thousands of observations. The main functions in this version are principal component analysis, cluster analysis, standardization and output data plot. In comparison with other well-known statistical analysis software programs, the same results are very well reproduced with MSAP-1.0. The format of the input data file was designed in a way convenient for the management of experimental survey data or preparation from other analysis procedures at the Institute.
\end{abstract}

Keywords: multivariate data analysis, principal component analysis, cluster analysis.

Classification numbers: 29.85.-c, 02.50.Sk.

\section{INTRODUCTION}

In the modern trend of survey data, multi-dimension information is often observed in many cases of research and application. In these situations, the data reduction process or multivariate statistical analysis method should be performed in order to determine whether any distinct groups or distributions are present in the input data sheet that supports a meaningful interpretation in the research topic such as archeological, geological, environmental, etc.

Based upon a data set of elemental concentrations, for a particular specimen, questions that we hope to answer are: (i) Where did the specimen come from? (ii) From what raw materials was the specimen made? (iii) Was the specimen made at the same time and in the same place as (C)2017 Vietnam Academy of Science and Technology 
other specimens? [1]. In our case, the archaeological brick and clay samples have been collected from a number of archaeological sites in Vietnam, and the concentrations of more than 28 elements in these specimens are determined by the reactor based neutron activation analysis (NAA) method. Accordingly, the principal component analysis (PCA) and cluster analysis (CA) methods are required to investigate the correlation of the brick and clay samples, and also to identify the similarities and differences between groups of brick specimens. The variations of an original multivariate data set are usually under indirect observation, but after being treated by PCA, the optimal visualization of variance can be presented with a high degree of explanation [2], in which a new space of principal component scores with maximal variance is obtained within the linear combination of the initial variables and eigenvectors as the following expressions [3]. Suppose that the initial data sheet is prepared as an $n \times p$ matrix $\mathbf{A}$, where $\mathrm{n}$ is the number of the observation vectors, and $\mathrm{p}$ is the number of variables of each vector.

$$
\mathbf{A}=\left[\begin{array}{cccc}
a_{11} & a_{12} & \ldots & a_{1 p} \\
a_{21} & a_{22} & \ldots & a_{2 p} \\
& & & \\
\vdots & & & \\
a_{n 1} & a_{n 2} & \ldots & a_{n p}
\end{array}\right]
$$

The covariance matrix $\mathbf{S}$ of $\mathbf{A}$, and the eigenvector matrix $\mathbf{X}$ are defined as:

$$
\begin{gathered}
\mathbf{S}_{j k}=\frac{1}{n-1} \sum_{i=1}^{n}\left(a_{i j}-\overline{a_{j}}\right)\left(a_{i k}-\overline{a_{k}}\right) \\
\{j=1, \ldots, p ; k=1, \ldots, p\}, \\
(\mathbf{S}-\lambda \mathbf{I}) \mathbf{X}=0
\end{gathered}
$$

where $\lambda$ is the eigen-value (column matrix), and $\mathbf{I}$ is the unity matrix.

We can determine the $\lambda$ and $\mathbf{X}$ matrices from the condition of $|\mathbf{A}-\lambda \mathbf{I}|=0$, and then the principal components (PCA scores) can be calculated as the following linear combinations:

$$
\begin{gathered}
y_{j}=\left(x_{j 1}, x_{j 2}, x_{j 3}, \ldots, x_{j p)}^{T}\left(a_{j 1}, a_{j 2}, a_{j 3}, \ldots, a_{j p}\right)=\sum_{i=1}^{p} x_{j i} a_{j i}\right. \\
y_{1}=x_{11} a_{1}+x_{12} a_{2}+x_{13} a_{3}+\ldots+x_{1 p} a_{p} \\
y_{2}=x_{21} a_{1}+x_{22} a_{2}+x_{23} a_{3}+\ldots+x_{2 p} a_{p} \\
y_{3}=x_{31} a_{1}+x_{32} a_{2}+x_{33} a_{3}+\ldots+x_{3 p} a_{p} \\
y_{4}=x_{41} a_{1}+x_{42} a_{2}+x_{43} a_{3}+\ldots+x_{4 p} a_{p}
\end{gathered}
$$

where $y$ : principal component scores, $a$ : linear combination parameter (eigenvector), $p$ : size of variable.

In addition, the cluster analysis is another multivariate analysis approach to measure the dissimilarity between specimens using Euclidean distances. The goal is to find an optimal grouping for which the specimens within each cluster are similar, but the clusters or groups are dissimilar to each other. The result of cluster analysis is generally presented in form of a dendrogram that shows the order and level of specimen clustering. Because the interpretation from a specific 
dendrogram is highly subjective, it is normally only used to identify possible groups, and after that other techniques are employed for group refinement and classification [1,4]. The Euclidean distance between two vectors $\mathbf{x}=\left(x_{1}, x_{2}, \ldots, x_{p}\right)$ and $\mathbf{y}=\left(y_{1}, y_{2}, \ldots, y_{p}\right)$ is defined as:

$$
d(x, y)=\sqrt{\sum \frac{1}{S}\left(x_{i}-y_{i}\right)^{2}}
$$

where $S$ is the covariance matrix of $A$ and $d(x, y)$ is Euclidean distance between vectors $\mathbf{x}$ and $\mathbf{y}$.

In this work, we developed a new computer program, so-called MSAP-1.0 to perform the above-mentioned calculations within the multivariate data analysis techniques. In this preliminary version of the program, the dimensions of a given data set to be analyzed are up to 50 variables and thousands of observations. The main functions in this version are principal component analysis, cluster analysis, standardization and output data plot. In comparison with the SPSS program, a well-known statistical analysis software, the same results are very well reproduced with MSAP1.0. The format of the input data file was designed in a way that is convenient for the management of experimental survey data or preparation from other analysis procedures at the Dalat Nuclear Research Institute.

\section{DEVELOPMENT OF THE COMPUTER PROGRAM MSAP-0.1}

Based on the multivariate statistical analysis method, a new C++ computer program, so-

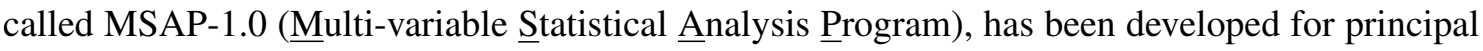
component analysis, cluster analysis, standardization, and output data plot. The program was tested and applied in the processing and interpretation of multi-dimensional measured data from NAA studies of archaeological samples collected from archaeological sites in Vietnam. The format structure of an input file and the window interface are presented in Fig. 1 and Fig. 2.

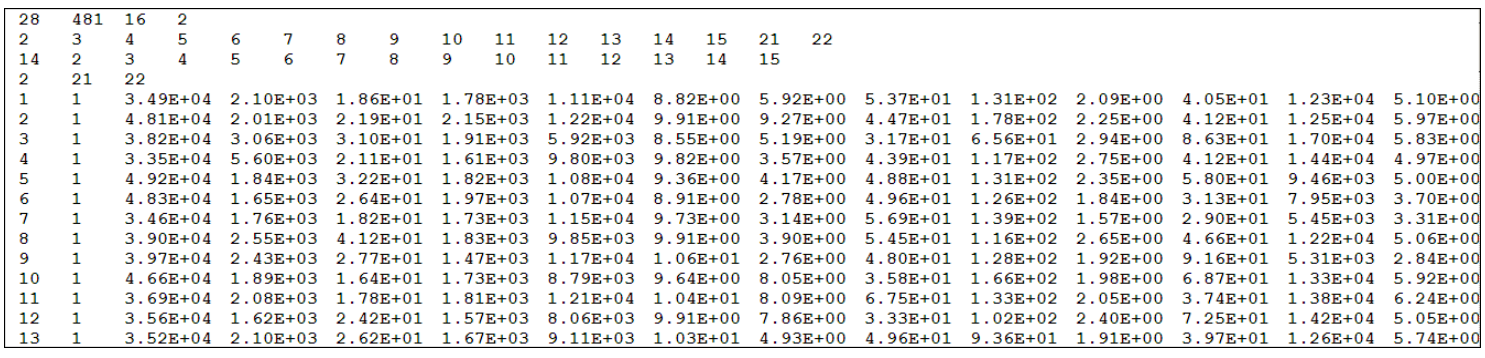

Fig. 1. The input file format for the MSAP-1.0 program.

\section{II.1. Test of the program}

The MSAP-1.0 program has been tested for validation by making comparisons under the same input data with the well-known SPSS-16.0 program [5]. The testing input data was selected from the elemental concentrations of five elements (As, $\mathrm{La}, \mathrm{Lu}, \mathrm{Nd}$ and $\mathrm{Sm}$ ) for 61 geological samples, as seen in Table 1. The input file for MSAP-1.0 is shown in Fig. 2. The output results of eigenvalues, eigenvectors and principal components (PCA scores) obtained in the testing process in comparison with the SPSS-16.0 program are presented in Tables 2-3 and Figures 3-4. 
Table 1. The input data of elemental concentrations used in testing the program.

\begin{tabular}{|c|c|c|c|c|c|c|c|c|c|c|c|}
\hline $\begin{array}{l}\text { Sample } \\
\text { ID }\end{array}$ & $\begin{array}{l}\text { As } \\
(\mathbf{p p m})\end{array}$ & $\begin{array}{l}\text { La } \\
(\mathbf{p p m})\end{array}$ & $\begin{array}{l}\text { Lu } \\
(\mathbf{p p m})\end{array}$ & $\begin{array}{l}\text { Nd } \\
(\mathrm{ppm})\end{array}$ & $\begin{array}{l}\text { Sm } \\
(\mathbf{p p m})\end{array}$ & $\begin{array}{l}\text { Sample } \\
\text { ID }\end{array}$ & $\begin{array}{l}\text { As } \\
(\mathbf{p p m})\end{array}$ & $\begin{array}{l}\text { La } \\
(\mathbf{p p m})\end{array}$ & $\begin{array}{l}\text { Lu } \\
(\mathbf{p p m})\end{array}$ & $\begin{array}{l}\text { Nd } \\
(\mathbf{p p m})\end{array}$ & $\begin{array}{l}\text { Sm } \\
(\mathbf{p p m})\end{array}$ \\
\hline M1 & 6.902 & 35.822 & 0.3111 & 28.978 & 5.716 & M32 & 7.404 & 35.28 & 0.2951 & 29.31 & 5.43 \\
\hline M2 & 8.898 & 34.58 & 0.3202 & 29.78 & 5.795 & M33 & 7.474 & 33.66 & 0.303 & 30.02 & 5.481 \\
\hline M3 & 8.861 & 33.18 & 0.2924 & 32.444 & 5.534 & M34 & 8.607 & 35.32 & 0.3226 & 31.95 & 5.851 \\
\hline M4 & 5.732 & 39.5 & 0.3218 & 31.35 & 6.141 & M35 & 10.139 & 35.52 & 0.3261 & 30.98 & 5.702 \\
\hline M5 & 7.28 & 39.48 & 0.3203 & 32.91 & 6.161 & M36 & 7.799 & 34.74 & 0.3132 & 30.39 & 5.627 \\
\hline M6 & 6.452 & 37.59 & 0.3469 & 31.31 & 5.973 & M37 & 6.982 & 33.15 & 0.2945 & 28.19 & 5.247 \\
\hline M7 & 6.773 & 35.31 & 0.3026 & 30.29 & 5.485 & M38 & 6.007 & 38.03 & 0.324 & 31.31 & 5.916 \\
\hline M8 & 8.507 & 35.17 & 0.3231 & 30.5 & 5.64 & M39 & 10.213 & 36.7 & 0.3252 & 31.16 & 5.949 \\
\hline M9 & 7.122 & 31.93 & 0.2588 & 27.08 & 4.888 & M40 & 7.651 & 34.52 & 0.2935 & 29.93 & 5.55 \\
\hline M10 & 5.663 & 36.4 & 0.2947 & 32 & 5.482 & M41 & 6.599 & 33.72 & 0.275 & 26.46 & 5.184 \\
\hline M11 & 9.29 & 39.66 & 0.3186 & 33.41 & 5.929 & M42 & 9.334 & 36.75 & 0.3308 & 28.84 & 5.942 \\
\hline M12 & 8.603 & 34.74 & 0.3215 & 30.63 & 5.664 & M43 & 13.092 & 39.85 & 0.4643 & 36.02 & 6.879 \\
\hline M13 & 8.713 & 36.63 & 0.3049 & 32.46 & 5.604 & M44 & 14.267 & 43.35 & 0.4602 & 36.28 & 7.37 \\
\hline M14 & 7.32 & 32.24 & 0.2925 & 27.77 & 5.189 & M45 & 15.641 & 39.54 & 0.4097 & 33.68 & 6.559 \\
\hline M15 & 9.794 & 36.47 & 0.3047 & 31.01 & 5.692 & M46 & 11.852 & 42.73 & 0.4461 & 33.33 & 6.956 \\
\hline M16 & 8.488 & 36.66 & 0.3313 & 32.39 & 5.808 & M47 & 15.991 & 42.83 & 0.452 & 37.09 & 7.208 \\
\hline M17 & 7.764 & 37.37 & 0.3003 & 31.48 & 5.837 & M48 & 12.598 & 39.59 & 0.4517 & 33.74 & 6.802 \\
\hline M18 & 7.061 & 33.43 & 0.3096 & 31.39 & 5.44 & M49 & 15.394 & 42.73 & 0.4584 & 35.51 & 7.141 \\
\hline M19 & 8.677 & 36.63 & 0.3625 & 29.63 & 5.838 & M50 & 14.755 & 42.57 & 0.4406 & 33.57 & 7.171 \\
\hline M20 & 8.399 & 35.78 & 0.337 & 30.06 & 5.627 & M51 & 11.783 & 43.22 & 0.3836 & 36.97 & 6.994 \\
\hline M21 & 7.737 & 36.05 & 0.3185 & 28.55 & 5.576 & M52 & 12.144 & 45.8 & 0.436 & 45.65 & 7.451 \\
\hline M22 & 6.458 & 29.46 & 0.2868 & 25.3 & 4.806 & M53 & 13.392 & 46.42 & 0.4155 & 42.41 & 7.635 \\
\hline M23 & 7.195 & 31.74 & 0.2858 & 26.9 & 5.034 & M54 & 10.401 & 49.9 & 0.4247 & 42.11 & 7.692 \\
\hline M24 & 10.135 & 38.33 & 0.3192 & 31.51 & 5.983 & M55 & 15.039 & 52.74 & 0.4003 & 47.88 & 7.769 \\
\hline M25 & 8.5 & 36.84 & 0.3187 & 29.29 & 5.656 & M56 & 13.576 & 44.4 & 0.4228 & 38.91 & 7.41 \\
\hline M26 & 8.802 & 35.88 & 0.3172 & 30.99 & 5.661 & M57 & 11.513 & 44.91 & 0.4179 & 42.04 & 7.365 \\
\hline M27 & 8.953 & 35.67 & 0.3115 & 31.48 & 5.964 & M58 & 10.522 & 41.39 & 0.4432 & 40.81 & 6.933 \\
\hline M28 & 7.923 & 35.09 & 0.309 & 28.15 & 5.682 & M59 & 8.661 & 43.7 & 0.3953 & 44.17 & 7.23 \\
\hline M29 & 9.755 & 36.89 & 0.3147 & 32.37 & 6.021 & M60 & 12.011 & 43.46 & 0.3932 & 38.67 & 7.229 \\
\hline M30 & 9.118 & 37.28 & 0.3305 & 32.89 & 6.044 & M61 & 11.801 & 47.13 & 0.4294 & 43.01 & 7.723 \\
\hline M31 & 11.367 & 43.3 & 0.4781 & 39.39 & 7.492 & & & & & & \\
\hline
\end{tabular}


Table 2. Results of calculated eigenvalues (variance explained).

\begin{tabular}{|c|c|c|c|c|c|c|}
\hline \multirow{2}{*}{ Component } & \multicolumn{3}{|c|}{ SPSS-16.0 program } & \multicolumn{3}{c|}{ MSAP-1.0 program } \\
\cline { 2 - 8 } & Eigenvalue & \% of variance & Cumulative \% & Eigenvalue & \% of variance & Cumulative \% \\
\hline 1 & 4.3239 & 86.477 & 86.477 & 4.2530 & 86.477 & 86.477 \\
\hline 2 & 0.4355 & 8.710 & 95.187 & 0.4284 & 8.710 & 95.187 \\
\hline 3 & 0.1483 & 2.966 & 98.153 & 0.1459 & 2.966 & 98.153 \\
\hline 4 & 0.0774 & 1.548 & 99.701 & 0.0761 & 1.548 & 99.701 \\
\hline 5 & 0.0149 & 0.299 & 100.0 & 0.0147 & 0.299 & 100.0 \\
\hline
\end{tabular}

Table 3. Results of calculated eigenvectors in comparison with SPSS-16.0 program.

\begin{tabular}{|c|c|c|c|c|c|c|c|c|c|}
\hline \multicolumn{4}{|c|}{ Eigenvectors calculated with SPSS-16.0 } & \multicolumn{4}{c|}{ Eigenvectors calculated with MSAP-1.0 } \\
\hline-0.413 & -0.698 & 0.582 & -0.053 & -0.027 & 0.413 & -0.698 & -0.582 & 0.053 & -0.027 \\
\hline-0.458 & 0.350 & 0.136 & 0.679 & -0.434 & 0.458 & 0.350 & -0.136 & -0.679 & -0.434 \\
\hline-0.447 & -0.333 & -0.747 & -0.180 & -0.313 & 0.447 & -0.333 & 0.747 & 0.180 & -0.313 \\
\hline-0.440 & 0.519 & 0.243 & -0.683 & -0.110 & 0.440 & 0.519 & -0.242 & 0.683 & -0.110 \\
\hline-0.476 & 0.102 & -0.158 & 0.193 & 0.837 & 0.476 & 0.102 & 0.158 & -0.193 & 0.837 \\
\hline
\end{tabular}

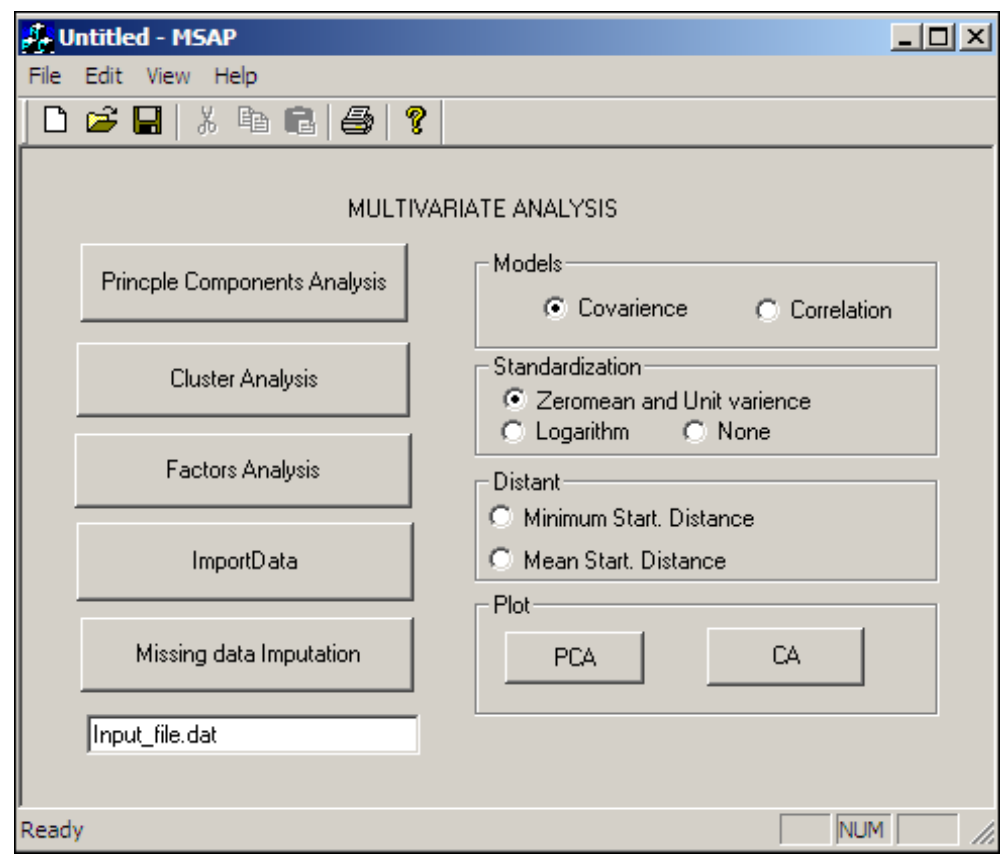

Fig. 2. The window interface of MSAP-1.0. 


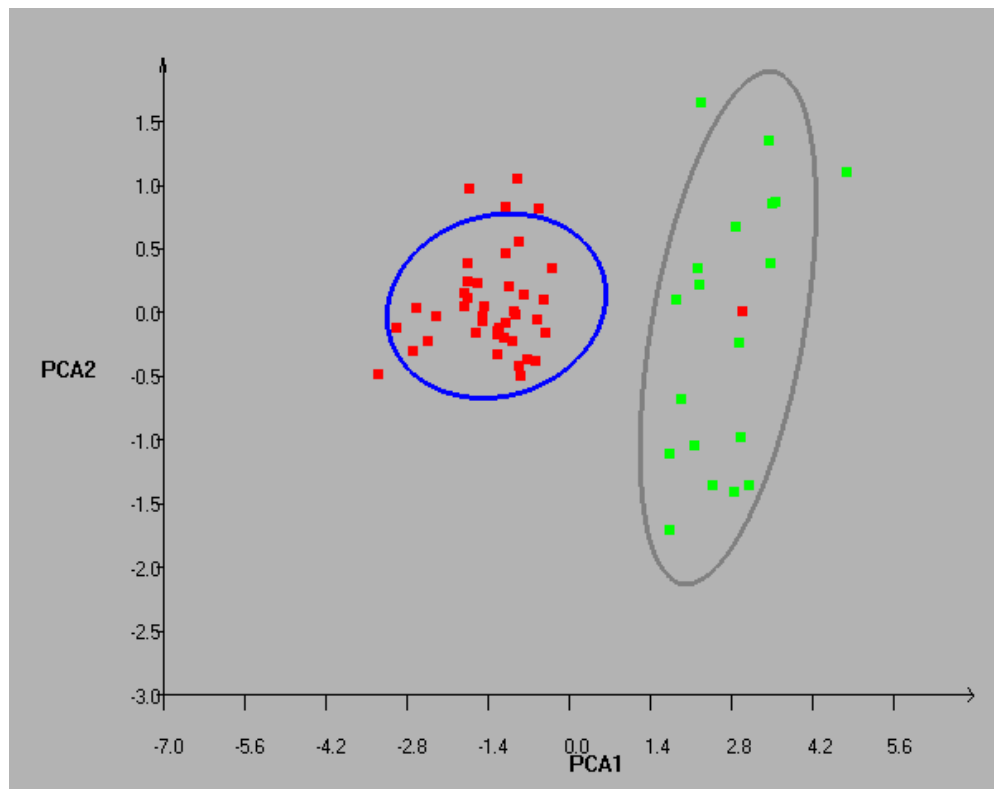

Fig. 3. Result of PCA scores plot by MSAP-1.0.

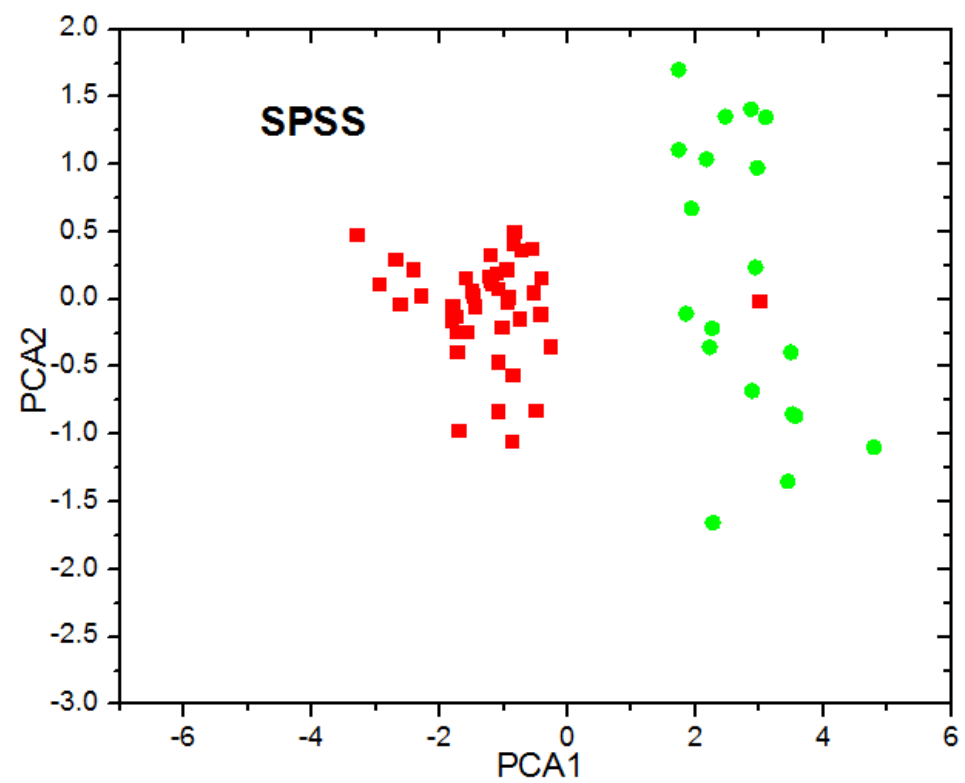

Fig. 4. Result of PCA sores plot from SPSS-16.0.

From the output values of the testing result above, both the programs SPSS-16.0 and MSAP-1.0, produce the similar output results of eigenvalues, eigenvectors and PCA scores. In 
some cases, the signs of eigenvectors from the two programs are different, but they are also identical because of random sign property of the eigenvector matrix. Based upon the comparison results, we can state that the MSAP-1.0 program can be used to conduct the principal component analysis, cluster analysis, standardization and output data plot for interpretations with multivariate data source.

\section{II.2. Application of the program}

The MSAP-1.0 program was applied for the PCA analysis and meaning interpretation of experimental multivariate data from NAA studies of archaeological samples collected from the archaeological sites in Lam Dong (Cat Tien) and Quang Nam (My Son) provinces of Vietnam. The results of principal component analysis for NAA data of the brick specimens and the clay samples collected in Cat Tien - Lam Dong province and the clay samples from Duy Xuyen Quang Nam province are presented in the Figs. 5-6.

The results of calculations within PCA method are given in Fig. 5. From this figure, we can recognize the difference between the Group1 and Group2 which were from different provenances. In the projection view on the plane of PC1 versus PC3, Fig. 6, the difference between the clay group (group 2) and the brick group (group 1) is presented. The distinction can be explained by the fact that the concentrations of some elements were changed during burning process for brick. These elements could be Al, Mn, K, Ga, Fe, Co and Hf (PC3). The PC1 is contributed by the 8 main elements as follows: $\mathrm{Al}, \mathrm{Ti}, \mathrm{V}, \mathrm{Rb}, \mathrm{Sc}, \mathrm{Cr}, \mathrm{Cs}$ and $\mathrm{Th}$; as the same way PC2 (7 elements): Dy, Na, La, Sm, Nd, Ce and Eu; PC3 (7 elements): Al, Mn, K, Ga, Fe, Co and Hf; and PC4 (4 elements): K, Lu, Tb and $\mathrm{Yb}$. The values of loading factors larger than 0.25 are chosen (the bold values in Table 4).

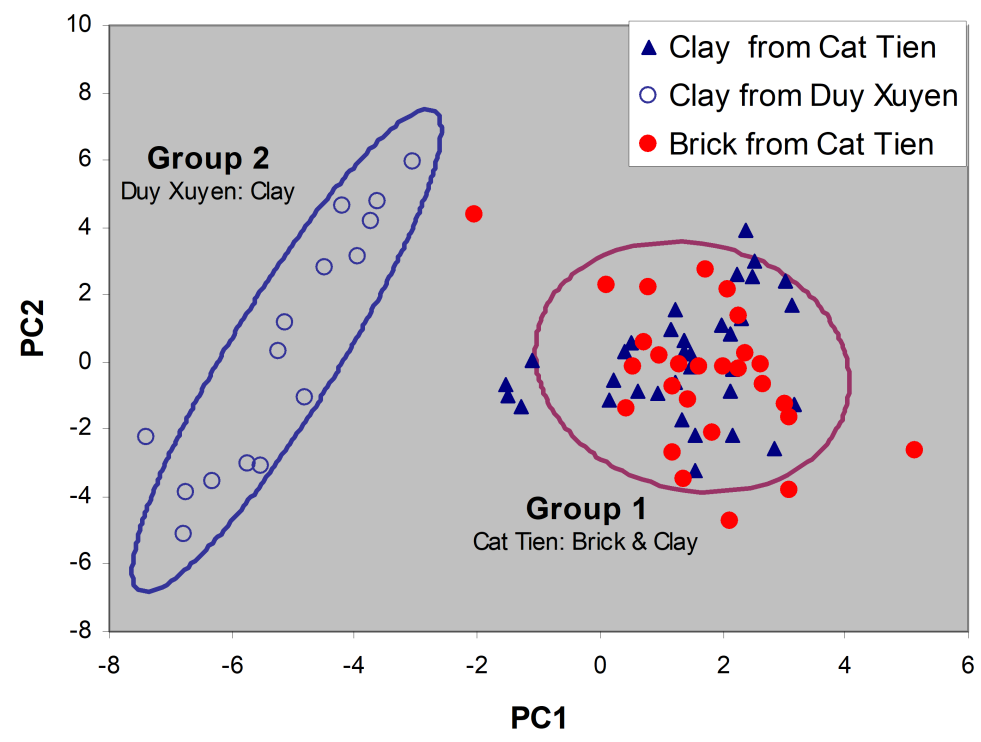

Fig. 5. Scattering plot of $\mathrm{PC} 1$ and $\mathrm{PC} 2$ for NAA data of Brick and Clay from Cat Tien and Clay from Duy Xuyen, Ellipses indicate 95\% confidence limits. 


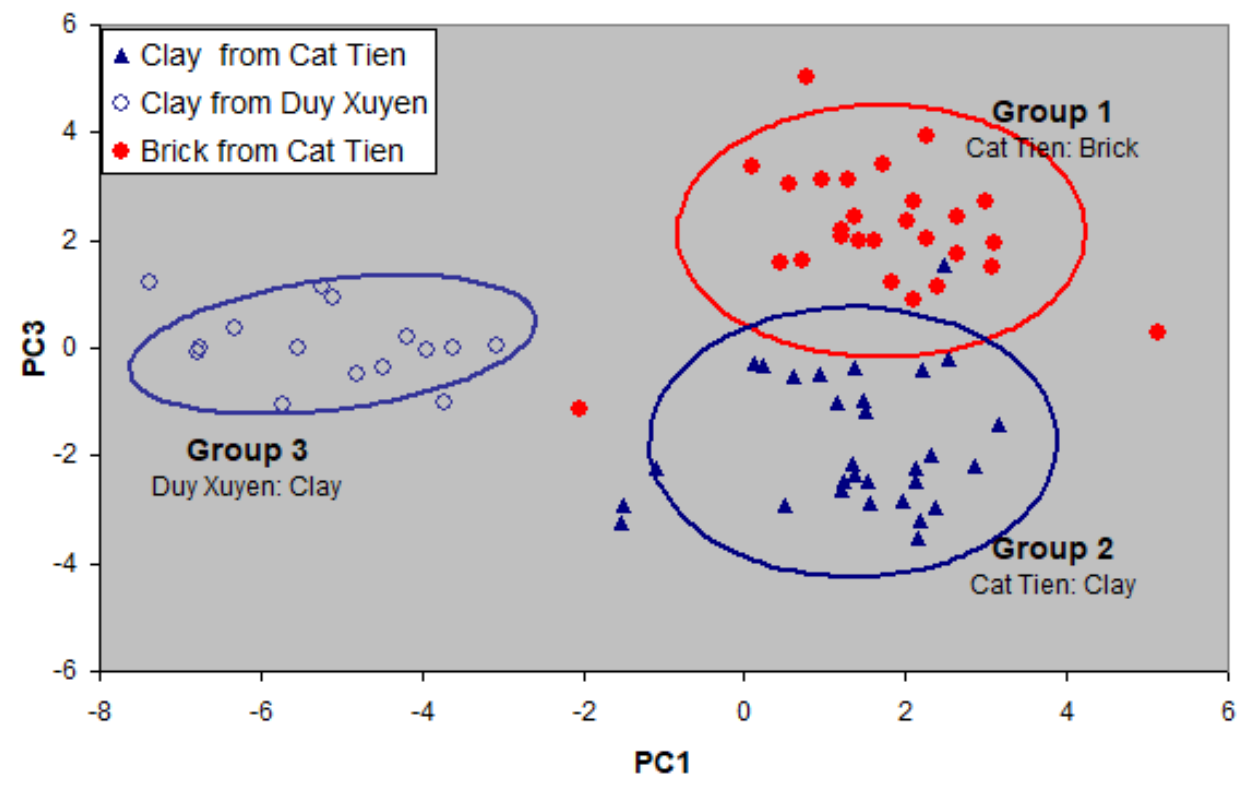

Fig. 6. Scattering plot of PC1 and PC3 for NAA data of brick and clay from Cat Tien and Duy Xuyen, Ellipses indicate $95 \%$ confidence limits.

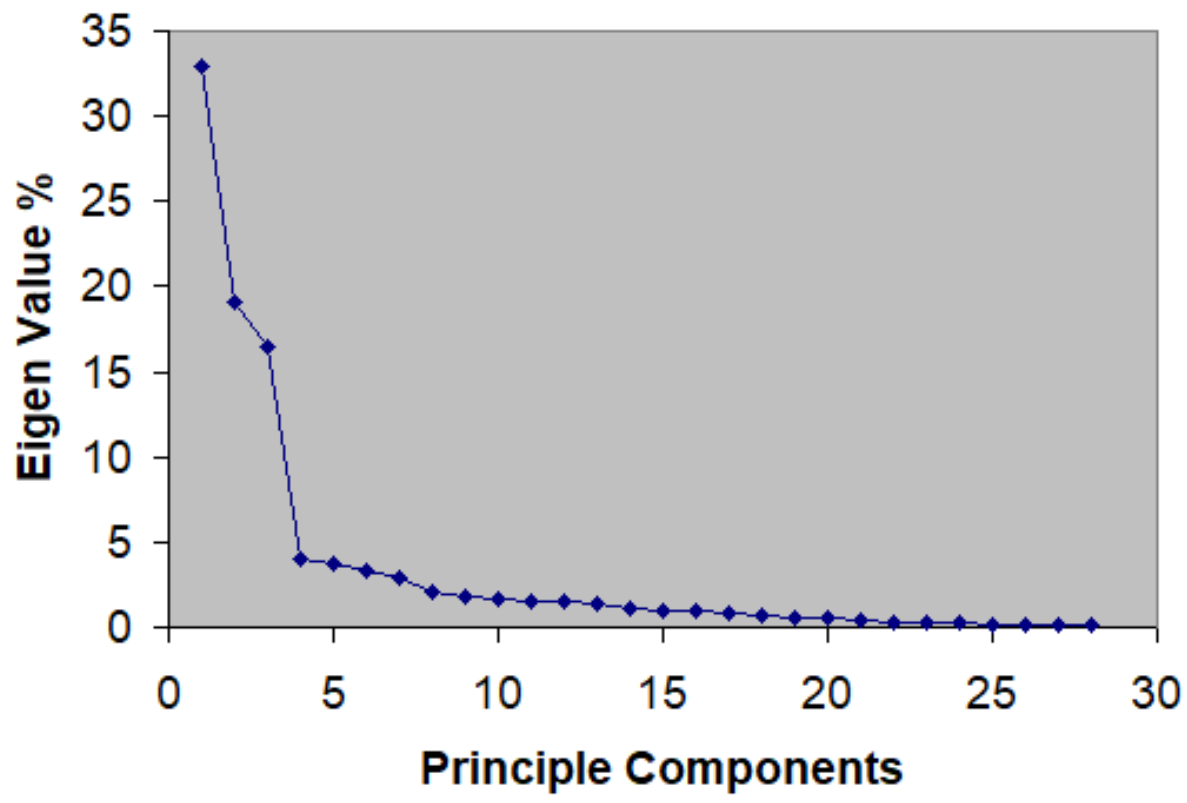

Fig. 7. Plot for eigenvalues of NAA data from Cat Tien's brick \& clay and Duy Xuyen's clay. 
Table 4. Contribution parameters for each element to the PC1, PC2, PC3 and PC4.

\begin{tabular}{|c|c|c|c|c|}
\hline Elements & PCA1 & PCA2 & PCA3 & PCA4 \\
\hline $\mathrm{Al}$ & 0.2554 & -0.0078 & -0.2493 & -0.0230 \\
\hline $\mathrm{Ti}$ & 0.2651 & -0.0089 & 0.1384 & 0.0202 \\
\hline $\mathrm{V}$ & 0.2757 & -0.0379 & -0.1109 & 0.0299 \\
\hline $\mathrm{Mn}$ & 0.0833 & 0.0577 & 0.3619 & 0.1811 \\
\hline Dy & 0.0517 & 0.3060 & 0.1283 & 0.0668 \\
\hline $\mathrm{Na}$ & 0.0605 & 0.2618 & 0.1424 & 0.2326 \\
\hline $\mathrm{K}$ & 0.1600 & 0.1002 & -0.2979 & 0.2543 \\
\hline $\mathrm{Ga}$ & 0.1969 & -0.0122 & -0.2786 & -0.0341 \\
\hline As & 0.2374 & -0.0343 & 0.2247 & 0.0692 \\
\hline $\mathrm{La}$ & -0.0871 & 0.3380 & -0.1548 & 0.1540 \\
\hline $\mathrm{Sm}$ & 0.0052 & 0.3748 & -0.0655 & 0.1739 \\
\hline $\mathrm{Rb}$ & 0.2531 & -0.0493 & -0.0052 & 0.1757 \\
\hline $\mathrm{Ba}$ & 0.1740 & 0.0031 & -0.0726 & 0.0303 \\
\hline $\mathrm{Nd}$ & -0.0382 & 0.3661 & -0.0698 & 0.1563 \\
\hline $\mathrm{Lu}$ & 0.0070 & 0.2428 & 0.2172 & -0.2504 \\
\hline $\mathrm{Sc}$ & 0.2936 & 0.0509 & -0.1464 & -0.0747 \\
\hline $\mathrm{Cr}$ & 0.2724 & 0.0406 & -0.0183 & -0.1049 \\
\hline $\mathrm{Fe}$ & 0.2124 & 0.0851 & 0.2644 & -0.0321 \\
\hline Co & 0.2246 & 0.0183 & 0.2898 & 0.0957 \\
\hline $\mathrm{Sb}$ & 0.2364 & -0.0109 & -0.0548 & -0.1139 \\
\hline $\mathrm{Cs}$ & 0.2911 & -0.0355 & -0.1514 & 0.0695 \\
\hline $\mathrm{Ce}$ & -0.1224 & 0.3530 & -0.0660 & -0.1480 \\
\hline $\mathrm{Eu}$ & 0.0162 & 0.3830 & -0.0529 & 0.0589 \\
\hline $\mathrm{Tb}$ & 0.0173 & 0.2239 & -0.0587 & -0.2545 \\
\hline $\mathrm{Yb}$ & 0.0809 & 0.1650 & -0.0003 & -0.7209 \\
\hline $\mathrm{Hf}$ & -0.0078 & 0.0616 & 0.4076 & -0.0011 \\
\hline $\mathrm{Ta}$ & 0.2477 & -0.0340 & 0.2305 & -0.0547 \\
\hline $\mathrm{Th}$ & 0.2663 & 0.0674 & -0.0691 & -0.0771 \\
\hline
\end{tabular}




\section{CONCLUSION}

A new computer program, called MSAP-1.0, has been developed for multi-dimension data analysis and data reduction. The program has been tested by comparison with the SPSS-16.0 program. This new program was successfully applied for multivariate statistical analysis of INAA data in archeological studies at the Dalat Nuclear Research Institute.

\section{REFERENCES}

[1] A. C. Rencher, Methods of Multivariate Analysis, 2 End, Wiley-Interscience, A John Wiley \& Sons, Inc. Publication, ISBN 0-471-41889-7, 2002.

[2] W. Hardle and L. Simar, Applied Multivariate Statistical Analysis, version 29th, MD-TECH, 2003.

[3] A. Buhagiar, Exploration and reduction of data using principal component analysis, Malta Medical Journal 14 (01) (2002) 27-35.

[4] P. Delicado, Statistics in Archaeology: New directions, Computer Applications in Archaeology meeting (CAA 1998), New Techniques For Old Times, 1998.

[5] SPSS Inc, Released 2007, SPSS for Windows, Version 16.0, Chicago, 2007. 